

\title{
Health security and environment capability of slick detection, characterization, and quantification in the offshore domain thanks to radar or optical imagery
}

Françoise Viallefont-Robinet, Sébastien Angelliaume, Laure Roupioz, Aymeric

Mainvis, Karine Caillault, Thibault Dartigalongue, Pierre-Yves Foucher,

Véronique Miegebielle, Dominique Dubucq

\section{To cite this version:}

Françoise Viallefont-Robinet, Sébastien Angelliaume, Laure Roupioz, Aymeric Mainvis, Karine Caillault, et al.. Health security and environment capability of slick detection, characterization, and quantification in the offshore domain thanks to radar or optical imagery. SPIE Remote Sensing 2019, Sep 2019, Strasbourg, France. 10.1117/12.2532098 . hal-02409705

\section{HAL Id: hal-02409705 \\ https://hal.science/hal-02409705}

Submitted on 13 Dec 2019

HAL is a multi-disciplinary open access archive for the deposit and dissemination of scientific research documents, whether they are published or not. The documents may come from teaching and research institutions in France or abroad, or from public or private research centers.
L'archive ouverte pluridisciplinaire HAL, est destinée au dépôt et à la diffusion de documents scientifiques de niveau recherche, publiés ou non, émanant des établissements d'enseignement et de recherche français ou étrangers, des laboratoires publics ou privés. 


\title{
Health Security and Environment capability of slick detection, characterization and quantification in the offshore domain thanks to radar or optical imagery
}

\author{
F. Viallefont-Robinet ${ }^{* a}$, S. Angelliaume ${ }^{\mathrm{b}}$, L. Roupioz ${ }^{\mathrm{a}}$, A. Mainvis ${ }^{\mathrm{a}}$, K. Caillault ${ }^{\mathrm{c}}, \mathrm{T}$. \\ Dartigalongue $^{\mathrm{a}}$, P. Y. Foucher ${ }^{\mathrm{a}}$, V. Miegebielle ${ }^{\mathrm{d}}$, D. Dubucq ${ }^{\mathrm{d}}$ \\ ${ }^{a}$ ONERA, Université de Toulouse F-31055 Toulouse - France \\ ${ }^{\mathrm{b}}$ ONERA, DEMR F-13661 Salon cedex Air - France \\ 'ONERA, DOTA Chemin de la Hunière, 91761 Palaiseau cedex - France \\ ${ }^{\mathrm{d}}$ TOTAL, Recherche, CSTJF, 6 Avenue Larribau, 64018 Pau, FRANCE
}

\begin{abstract}
During five years, in the frame of the NAOMI (New Advanced Observation Method Integration) research project, Total and ONERA have worked on radar and optical imagery to detect, characterize and quantify slicks at sea. Laboratory and pool measurements, physical modelling and offshore experiments have been combined to fully understand the signal collected over slick-covered area. As the measured signal is analytically expressed according to the geophysical parameters of the imaged slick, it enables to fully monitor the ocean surface: is a slick present? What kind of slick is it (extremely thin or not)? Is it a known product (existing in the data base)? Can the thickness be probed by the used of optical or radar device? What is the slick volume?
\end{abstract}

In the Health Security and Environment (HSE) context, an exhaustive measurement campaign can be done in order to create a data base with hydrocarbon or hydrocarbon emulsion signatures, extinction coefficients, skin depths, minimum thicknesses perceptible thanks to extinction and thickness values. Thus, it offers more processing options in the optic branch of the tool to monitor the slick.

Depending on the available data, optical and/or radar imagery, the capability of slick detection, characterization and quantification will be presented. After a recall of the HSE specificity, the paper will give an overview of the main features of the input data that is to say SAR and optical images. Then, based on modelling results, the optimal observation conditions for radar and optical imagery will be introduced. Afterwards, capability of detection will be described and illustrated for both the radar and the optical case. In the optical domain, the process will distinguish at least two classes: thin and thick. In the HSE context, a database can be used to identify some detected products. The last step is quantification. A sophisticated method, relying on L band radar imagery, will be used to identify pixels covered by a film, meaning presence of oil at the surface, and the ones for which the oil may be as droplets in the volume. The traditional use of SAR data is also extended to the estimation of the oil concentration within an oil and seawater mixture. For optical data, the most direct quantification process relies on automatic Bonn code classification. The code links a class with a range of thickness and computes a minimum and a maximum volume of product in each class. If the product is in the data base a more suited classification and volume assessment can be done. If the thickness is too thin (spectral signature due to absorption is too weak) or too thick (only the upper part of the product layer contributes to the signal), a thickness estimated thanks to pool experiment is associated to each class enabling to compute a volume per class and a global volume. In the other cases, in a near future, modelling would enable to assess the thickness. Concerning hydrocarbon emulsions, modelling in the optical domain is in progress in order to predict skin depth and to derive water content.

Keywords: Oil spill detection, offshore remote sensing, water-in-oil emulsion, oil slick thickness, oil spill volume, sea pollution 


\section{INTRODUCTION}

Total and ONERA have set up a large project named NAOMI standing for New Advanced Observation Method Integration. Among the issues addressed by this research project, one is devoted to detection, characterization and quantification of offshore hydrocarbons at sea surface. The project outputs will impact the exploration and the environment domains. Indeed, detection and monitoring of natural hydrocarbons at sea surface (seeps) are key elements in exploration as well as the detection and monitoring of anthropogenic hydrocarbons at sea surface (spills) are crucial for adapting the means to protect environment and clean sea surface.

The bibliography stressed the potential of radar and optical imagery for spill detection [1][2] and optical imagery ([3]-[6]) for hydrocarbons characterization and quantification. In the frame of NAOMI project, work has been performed to extend the radar detection capability toward characterization [7] and quantification [8][9] and to test and enhance optics capability in these fields. Choice has been made to associate laboratory, pool, airborne, and (when available) space-borne measurements, modelling and physically based image processing to progress on signal understanding and reach the project objectives.

The paper starts with HSE needs and then describes the data available for the study. Thanks to modelling, the optimal observation conditions are presented. An operational workflow with a radar branch and an optical one is described starting with detection, moving to characterization and ending with quantification. At each stage, example(s) of result will be given.

\section{HYGIEN, HEALTH AND SECURITY NEEDS}

One of the objectives of the NAOMI research project is to work on detection, characterization and quantification of offshore hydrocarbon at sea surface and particularly in oil slick extension, volume and location determination for environmental (HSE) applications. This concerns regular monitoring of offshore production facilities for eventual oil leakage detection or possible incidents occurring on sea surface (spill, boat, sewages...).

The objective of this monitoring is to detect hydrocarbon traces and their recurrence, identify and discriminate possible origins of these slicks, determine rapidly slick origin, location and extension. It's important to predict (with Metocean information) and monitor leak drift, in order to assist team in intervention strategy preparation, inform where intervention teams should take action, follow leakage evolution, and evaluate timing of areas impact. Knowledge of the nature, state (emulsified or not) and volume of the spilled product is key information to implement the appropriate intervention strategy.

\section{DATA OVERVIEW}

The main experimental data used in this paper have been collected by SETHI, the ONERA airborne sensor dedicated to the exploration of scientific applications of remote sensing [10]. The airborne system flew during an experimental campaign of radar and optical imagery: NOFO'2015. It was conducted 8-14 June 2015 during NOFO's oil-on-water exercise. This experiment usually aims at testing recovering systems of pollution at sea by hydrocarbons [10]. During the exercise, acquisitions were collected over the offshore spill areas (North Sea, near $59^{\circ} 59^{\prime} \mathrm{N}, 2^{\circ} 27^{\prime} \mathrm{E}$ ). In the following, we use images collected by the French airborne sensor on 9 June 2015. For the investigated experiment, the released product is an emulsion of mineral oil in water $\left(45 \mathrm{~m}^{3}\right.$ were discharged at sea), with a water content of $60 \%$. It consists of a mixture of seawater, Oseberg crude oil and a small addition of IFO 380 (Intermediate Fuel Oil or marine diesel oil, with viscosity of $380 \mathrm{~mm}^{2} . \mathrm{s}^{-1}$ ).

\subsection{Radar}

The spills have been imaged by a dual-frequency (X and L-band) radar sensor onboard SETHI with a spatial resolution of 0.5 and $1 \mathrm{~m}$ at X-band and L-band respectively and in a quad-polarimetric mode $(\mathrm{HH}, \mathrm{HV}, \mathrm{VH}$, VV). Illustration of X and L-band SAR images collected the 9 of June 2015 at 10:02 UTC in VV-polarization are given Figure 1. Within the lower part of the slick, the passage of a mechanical recovery boom, called MOS Sweeper [10], appears to leave behind a relatively clean sea surface (range from 4.1 to $4.2 \mathrm{~km}$ and azimuth from 3 to $4 \mathrm{~km}$ ). The lake left by the passage of a ship through the slick is also clearly seen (range around $4.0 \mathrm{~km}$ and azimuth from 2.0 to $4.9 \mathrm{~km}$ ). Wind and waves information was obtained from the Norwegian Meteorological Institute: wind came from $255^{\circ}$ with a speed measure at $10 \mathrm{~m}\left(\mathrm{U}_{10}\right)$ of $5 \mathrm{~m} \cdot \mathrm{s}^{-1}$. Significant wave height was about $1 \mathrm{~m}$. 

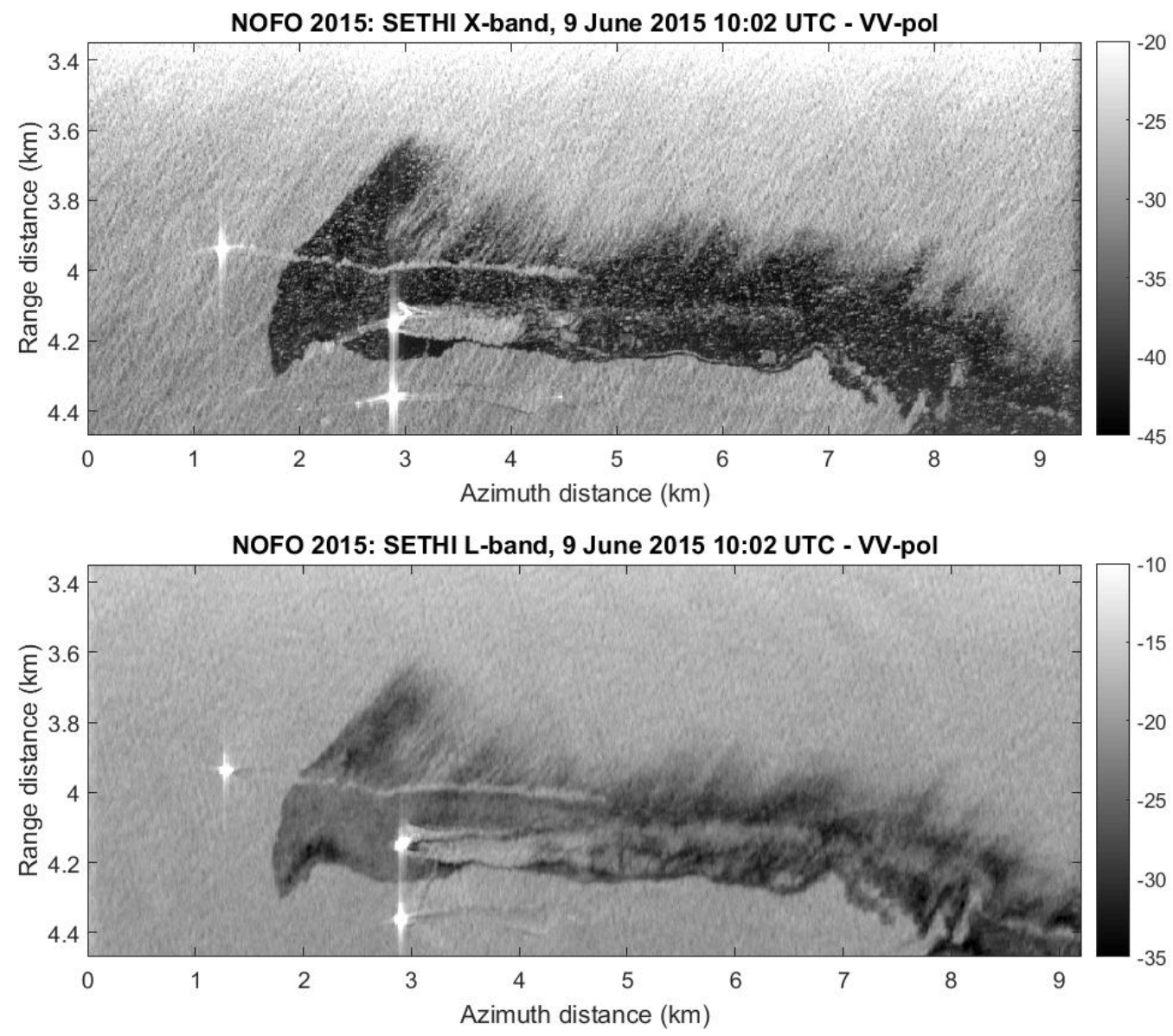

Figure 1: SAR images (slant range geometry) collected by SETHI at X-band (up) and L-band (down) during the NOFO experiment in June 2015.

\subsection{Optics}

The optical images range from pool [11] to sea [10], from 15m to satellite altitude and from multispectral to hyperspectral sensors. The Table 2 summarizes the optical images involved in this study. The main data are the CEDRE and the NOFO-2015 ones due to the a priori knowledge of the image content. It enables to appreciate the processes efficiency. The other images provide other kinds of content such as seaweeds or correspond to real cases, but without ground truth.

\begin{tabular}{|l|l|l|l|l|l|}
\hline Location & Content & Date & Sensor & Spectral features & $\begin{array}{l}\text { Spatial } \\
\text { resolution }\end{array}$ \\
\hline $\begin{array}{l}\text { CEDRE } \\
\text { pool }\end{array}$ & $\begin{array}{l}\text { Dedicated } \\
\text { spills }\end{array}$ & Sept-Oct 2017 & $\begin{array}{l}\text { HySpex } \\
\text { cameras VNIR } \\
\text { \& SWIR }\end{array}$ & Hyperspectral & $\begin{array}{l}\text { About } 1 \mathrm{~cm} \\
\mathrm{x} 1 \mathrm{~cm}\end{array}$ \\
\hline $\begin{array}{l}\text { North Sea } \\
\text { (NOFO2015 } \\
\text { experiment) }\end{array}$ & $\begin{array}{l}\text { Controlled } \\
\text { spill }\end{array}$ & $\begin{array}{l}09 / 06 / 2015 \\
(10 \mathrm{~h} 12 \text { UTC) }\end{array}$ & $\begin{array}{l}\text { HySpex } \\
\text { cameras VNIR } \\
\text { \& SWIR }\end{array}$ & Hyperspectral & $\begin{array}{l}\text { About } 2 \mathrm{~m} \mathrm{x} \\
2 \mathrm{~m}\end{array}$ \\
\hline Sri Lanka & Spill & $28 / 09 / 2018$ & $\begin{array}{l}\text { MSI Sentinel } \\
\text { 2B }\end{array}$ & $\begin{array}{l}10 \text { spectral } \\
\text { bands in VNIR } \\
3 \text { spectral bands } \\
\text { in SWIR }\end{array}$ & $\begin{array}{l}10 \mathrm{~m}, 20 \mathrm{~m}, \\
60 \mathrm{~m})\end{array}$ \\
\hline $\begin{array}{l}\text { France } \\
\text { (America } \\
\text { Grande) }\end{array}$ & Spill & $23 / 03 / 2019$ & $\begin{array}{l}\text { MSI Sentinel } \\
\text { 2A }\end{array}$ & $\begin{array}{l}10 \text { spectral } \\
\text { bands in VNIR } \\
3 \text { spectral bands }\end{array}$ & $\begin{array}{l}10 \mathrm{~m}, 20 \mathrm{~m}, \\
60 \mathrm{~m})\end{array}$ \\
\hline
\end{tabular}




\begin{tabular}{|l|l|l|l|l|l|}
\hline & & & & in SWIR & \\
\hline $\begin{array}{l}\text { France } \\
\text { (Corsica) }\end{array}$ & Spill & $09 / 10 / 2018$ & $\begin{array}{l}\text { MSI Sentinel } \\
\text { 2A }\end{array}$ & $\begin{array}{l}10 \quad \text { spectral } \\
\text { bands in VNIR } \\
3 \text { spectral bands } \\
\text { in SWIR }\end{array}$ & $\begin{array}{l}10 \mathrm{~m}, 20 \mathrm{~m}, \\
60 \mathrm{~m})\end{array}$ \\
\hline Baltic sea & Seaweeds & $28 / 09 / 2018$ & OLI Landsat 8 & $\begin{array}{l}\text { 6 spectral bands } \\
\text { in VNIR } \\
\text { 3 spectral bands } \\
\text { in SWIR }\end{array}$ & $30 \mathrm{~m},(15 \mathrm{~m})$ \\
\hline Shetlands & Seaweeds & $12 / 06 / 2016$ & OLI Landsat 8 & $\begin{array}{l}\text { 6 spectral bands } \\
\text { in VNIR } \\
\text { 3 spectral bands } \\
\text { in SWIR }\end{array}$ & $30 \mathrm{~m},(15 \mathrm{~m})$ \\
\hline
\end{tabular}

Table 1: Summary of the optical images used in the offshore study

\section{OPTIMAL OBSERVATION CONDITIONS}

\subsection{Radar}

The analytical model of the backscattered signal from ocean surfaces, covered or not by a thin oil film, is helpful to determine the optimal sensor settings to succeed in the detection of oil slicks on SAR imagery. Therewith, the radar contrast between slick-free and slick-covered ocean surfaces can be computed to identify the best combination of electromagnetic frequency / incidence angle. An example is given in Figure 2 with a wind speed of $9 \mathrm{~m} / \mathrm{s}$ in upwind configuration. In this case, the most effective sensor settings for oil detection are the incidence angles between $25^{\circ}$ and $45^{\circ}$ for the X-band ( $10 \mathrm{GHz}$ ), the angles greater than $25^{\circ}$ for the C-band (5 $\mathrm{GHz}$ ) and the angles greater than $40^{\circ}$ for the S-band (2-4 GHz). Also, it should be noted that the near-nadir angles should not be considered in the oil detection context due to a very low contrast. Therefore, it appears that the airborne sensor is better than the space sensor by offering a wider range of moderate incidence angles.

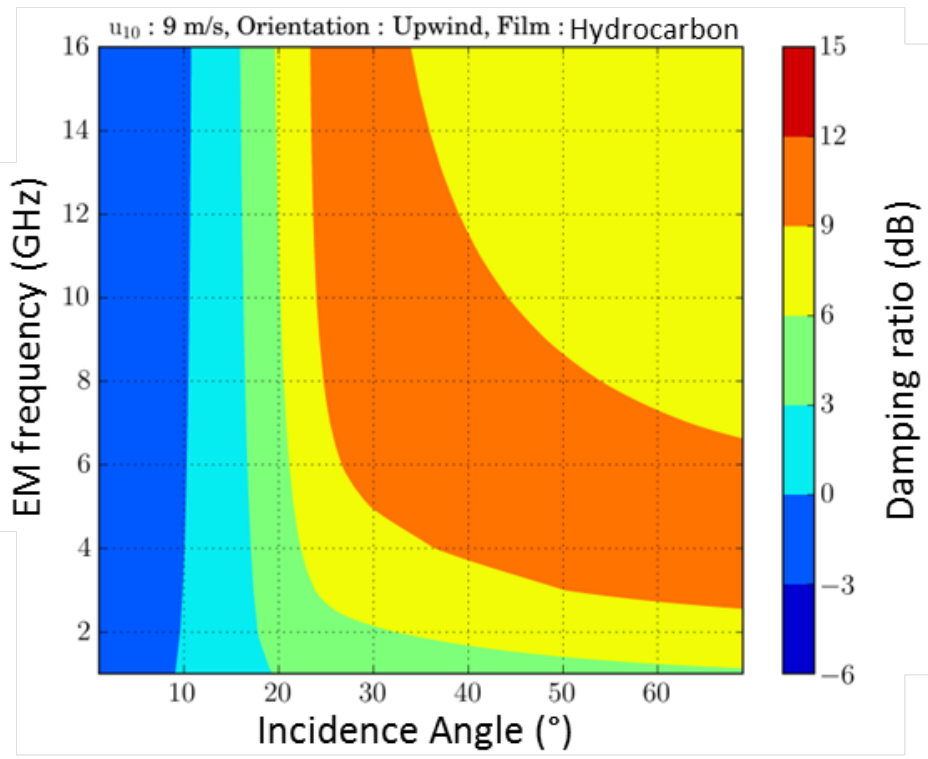

Figure 2 : Radar contrast between slick-free and slick-covered ocean surface (in $\mathrm{dB}$ ). The configuration is upwind and the wind speed is $9 \mathrm{~m} / \mathrm{s}$. 


\subsection{Optics}

In the case of a pure oil film the modelling can be used to determine for instance the optimal atmospheric conditions and the optimal spectral domain for data acquisition. For a layer oil at the water surface (without wave), modelling enables to quantify the impact in term of contrast between oil and water for different atmospheric conditions. An example is given in Figure 3 for a 100 $\mu \mathrm{m}$ layer of 15W40 motor oil, for a nadir view and a solar zenith angle of $50^{\circ}$. In this case as in all cases, the clear sky leads to the optimal contrast as the specular reflection of the atmospheric radiance is the stronger contributor to the observed signal. Modelling can also be used to determine the spectral domain in which contrast will be at its maximum. This is illustrated in Figure 4, still for the 15W40 motor oil. Contrast increases globally with wavelength all the more the layer is thin. This has to be tempered by the signal to noise ratio which is fairly weak usually after $2 \mu \mathrm{m}$.

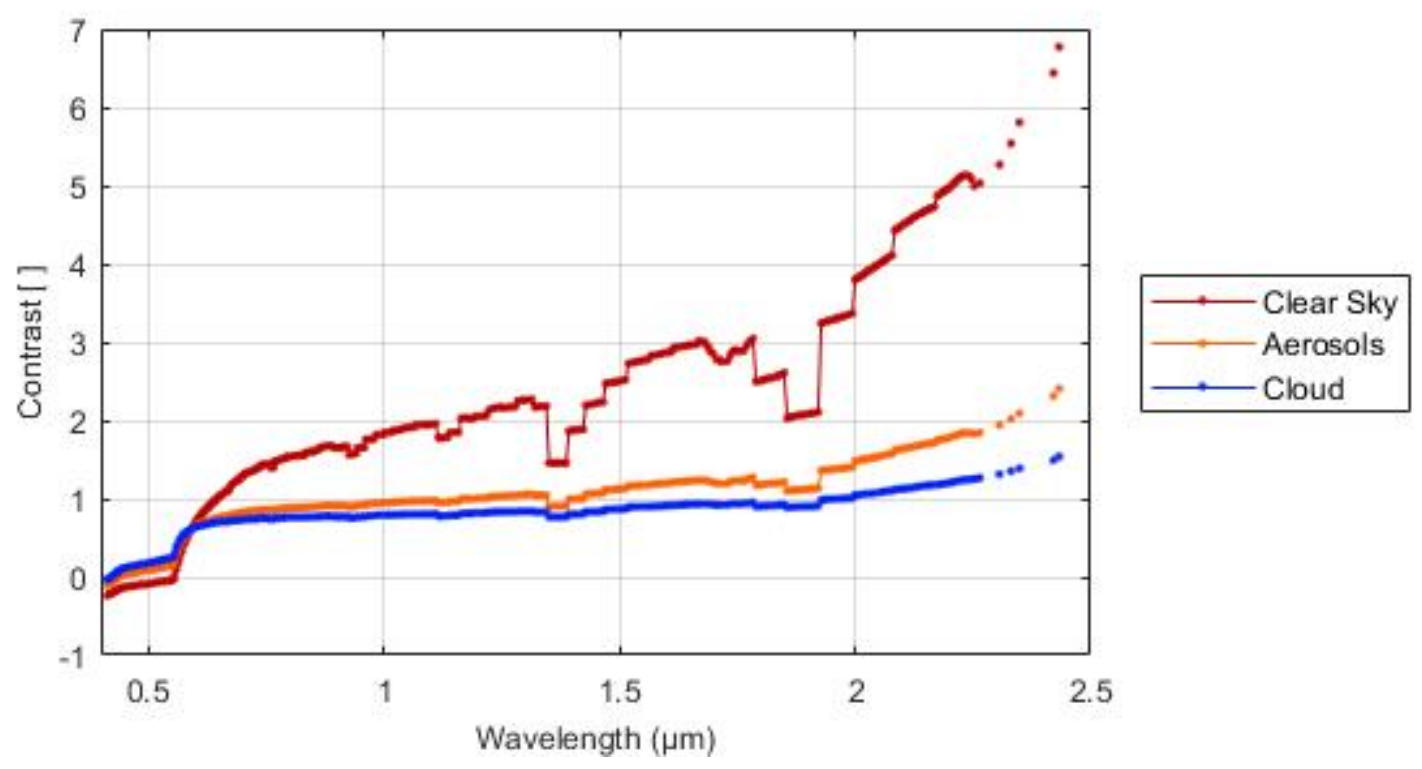

Figure 3 : Variation of contrast of a $100 \mu \mathrm{m}$ layer of $15 \mathrm{~W} 40$ motor oil for $50^{\circ}$ solar zenith angle, nadir view and various atmospheric conditions

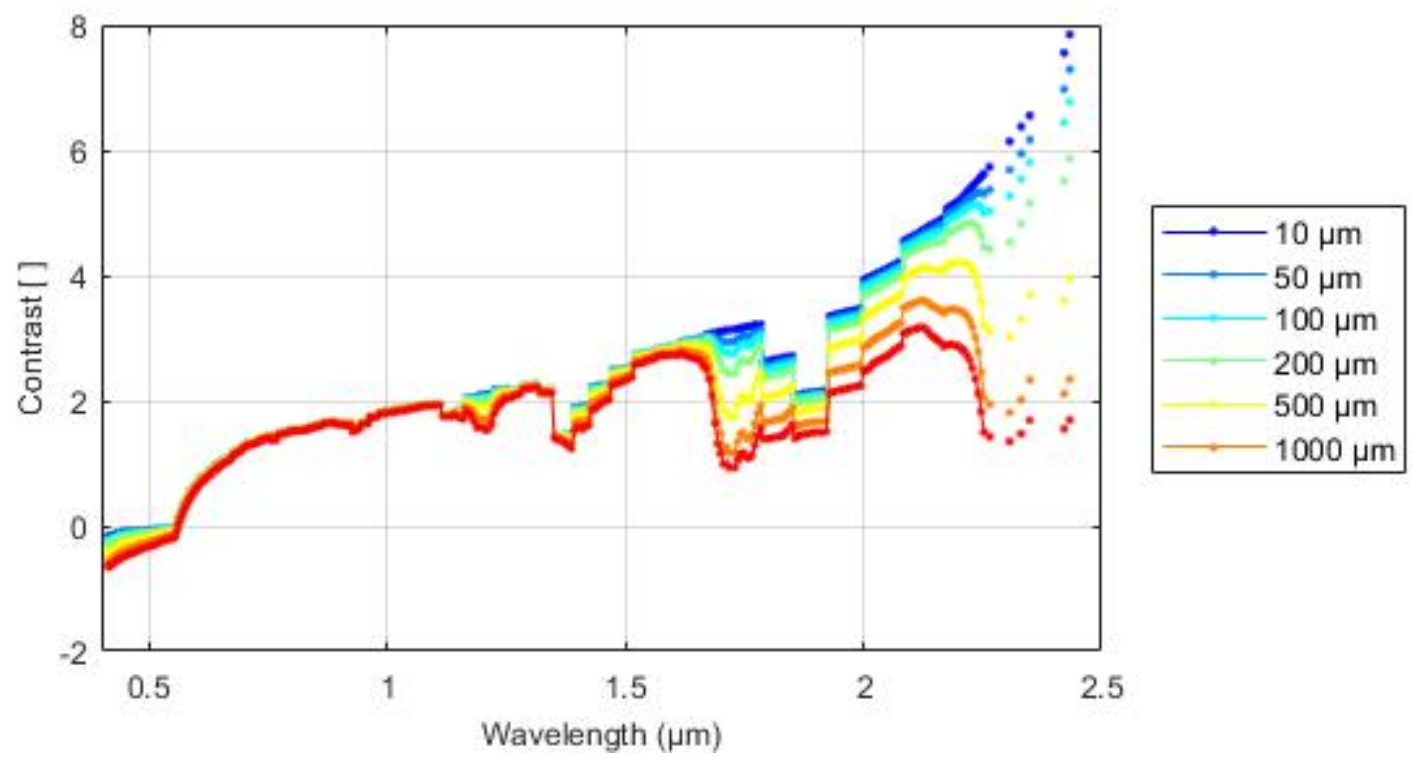

Figure 4: Variation of contrast of $15 \mathrm{~W} 40$ motor oil layers for $50^{\circ}$ solar zenith angle, nadir view and clear sky condition 


\section{WORKFLOW}

\subsection{Overview}

The diagram of Figure 5 gives an overview of the available workflow in case of an alert concerning spill at the sea surface. Starting with the first available data, probably radar, the data is injected in the processing chain. The first step in the radar branch of the workflow, is the detection which enables to detect slicks but also maybe lookalike. Depending on the features of the radar available data (SNR, polarization and frequency), a characterization of the detected areas can be done enabling to distinguish between thin surface film and oil mixture in the water column. The last step for data acquired in dual polarization in $\mathrm{L}$ band, is the volume fraction estimation. As soon as an optical acquisition is available, it is injected in the optical branch of the workflow, starting with detection thanks to indices and then going on with characterization using segmentation of the chosen index image. The characterization may go up to identification thanks the spectral libraries using spectral distance algorithms. The last step is the quantification which affects a thickness to a class of pixels and assesses the volume of the slick by multiplication of the thickness with the surface covered by the pixels of the considered class. All these steps will be detailed in the following subsections.

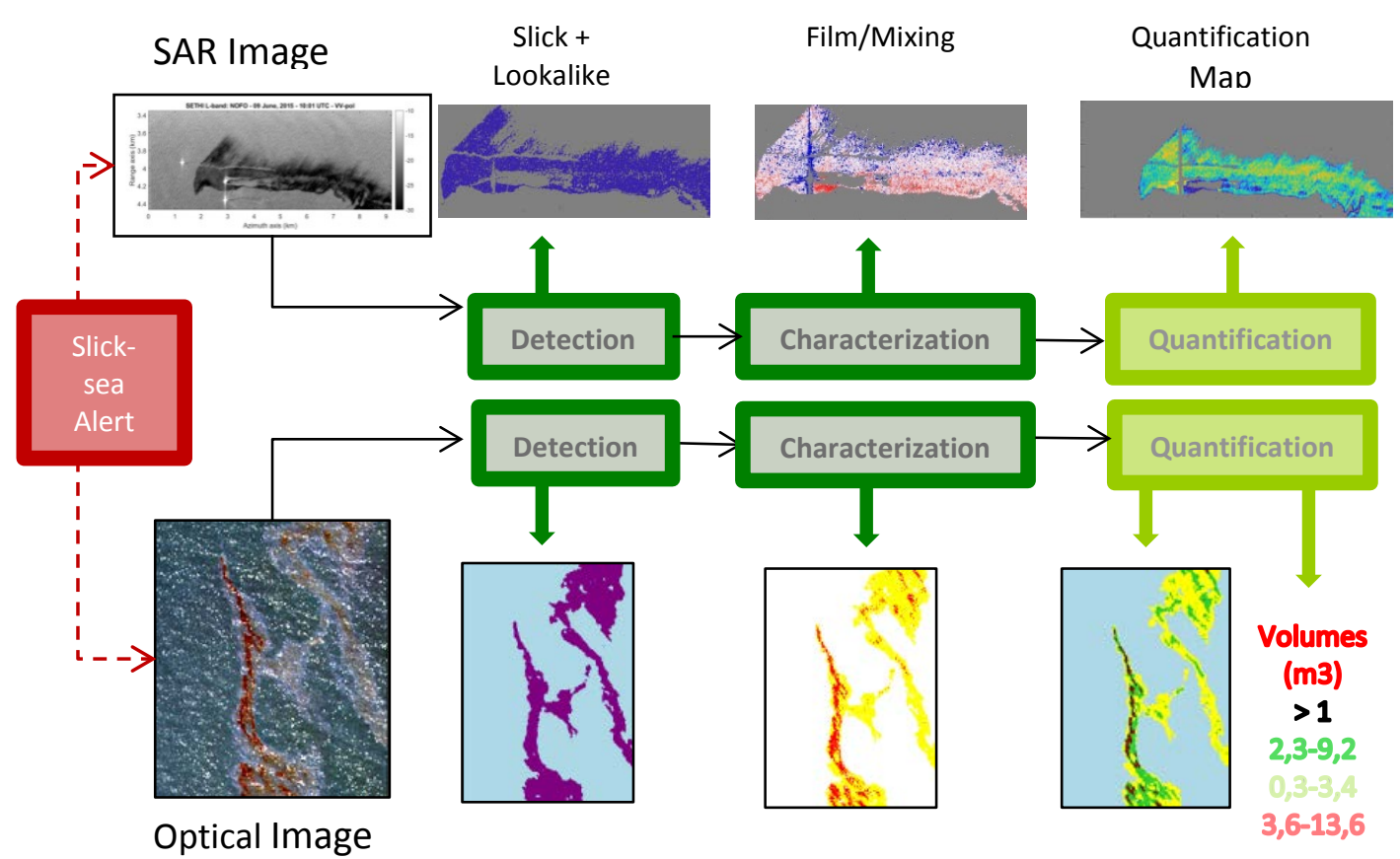

Figure 5: Overview of the workflow for slick detection, characterization and quantification

\subsection{Radar branch}

When hydrocarbons are spilled at sea, the oil can behave like a viscoelastic film floating on the surface or be mixed with seawater within the upper few centimeters of the water column. In the first case (thin film), radar backscattered power is mainly diminished through mechanical damping of Bragg-wavelength gravity-capillary waves. In the second, mixing of oil with seawater will lead to a reduction of the relative dielectric constant of the contaminated sea surface compared to the surrounding slick-free area. This will contribute to a decrease in the total radar backscattered power, along with suppression of the Bragg-wavelength gravity-capillary waves that are present due to the difference in surface tension and density.

Radar imaging is used in an operational context to detect and monitor marine pollution. When both HH and VV polarization are collected over the released substance, crucial information on the behavior [7][12] and quantity [8][9] of spilled product can also be provided by remote sensing radar data. Methodologies apply to oil spill 
monitoring by SAR imaging are given in the following. All are based on the polarization difference (PD) and the polarization ratio (PR), defined as

$$
\begin{gathered}
P D=\sigma_{V V}^{0}-\sigma_{H H}^{0} \\
P R=\frac{\sigma_{H H}^{0}}{\sigma_{V V}^{0}}
\end{gathered}
$$

where $\sigma_{p p}^{0}$ is the Normalized Radar Cross Section (NRCS) and p denotes either H or V polarization. PD is proportional to the spectral density of the ocean surface roughness and PR is mostly driven by the angle of incidence and the dielectric constant of the imaged surface. Thus, PD is an attractive parameter for detecting a film on the ocean surface which will mainly damped the sea surface roughness. PR is a good option to identify the presence of an oil and seawater mixture.

\section{Detection}

Many SAR parameters are proposed in the literature for detecting marine slick with SAR sensor. A comprehensive review is given in [13] as well as a quantitative study of their performance of detection. In this section, our goal is to go beyond detection and measure the effectiveness of cleaning operation, what is key information to get in an HSE context. Detecting the presence of oil at sea is one thing, to be sure of its absence is more challenging and the different forms that the oil can take when released at sea must be taken into account. The methodology proposed herein aims to take fully into account the information provided by polarimetric measurements. Firstly, we normalized the polarization difference to get a more easy-to-use parameter [7]

$$
N P D=1-\frac{P D}{P D_{\text {water }}}
$$

Then we define the OI (Oil Impact) parameter

$$
O I=N P D * P R
$$

which combines the effects on the EM signal of a surface film (NPD term) and an oil and water mixture (PR term), as both PR and NPD increase with the increasing impact of oil. This polarimetric feature can be used to detect oil on the sea surface whatever its behavior, it can also be used to quantify the effectiveness of clean-up operation. Indeed, we can easily observe the oil slick on the Oil Impact map (Figure 6) as well as the efficiency of the MOSS Sweeper boom as it left behind OI values equal to those obtained over the clean sea water around. The oil spill map given Figure 7 has been obtained by thresholding the OI parameter, without any other filtering except the spatial multi-looking (window size $7 \times 7$ ) to compute PD and PR and the boat masking using the copolarized phase difference. The threshold value, set to 0.5 in Figure 7, can be adapted, depending on the user needs in term of false alarm rate. Note that as high frequency radar imagery is more efficient than low frequency for marine slick detection, those results have been obtained using X-band SAR data only.

NOFO 2015: SETHI X-band, 9 June 2015 10:02 UTC Oil Impact (OI) parameter

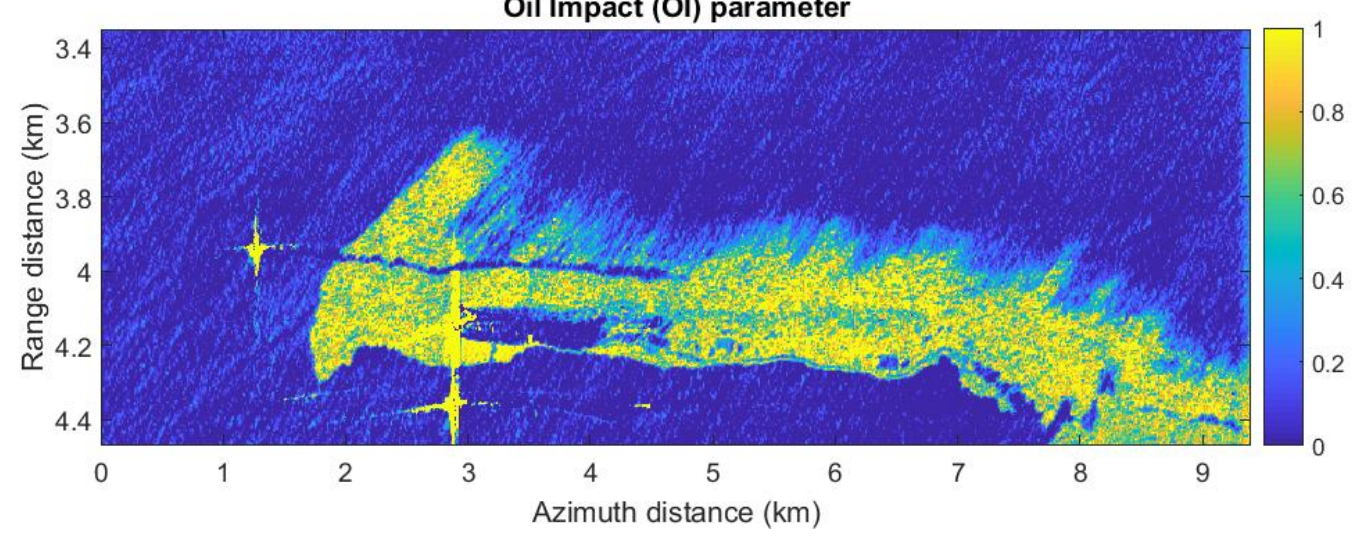

Figure 6: OI parameter computed with SETHI X-band SAR data - NOFO-2015 


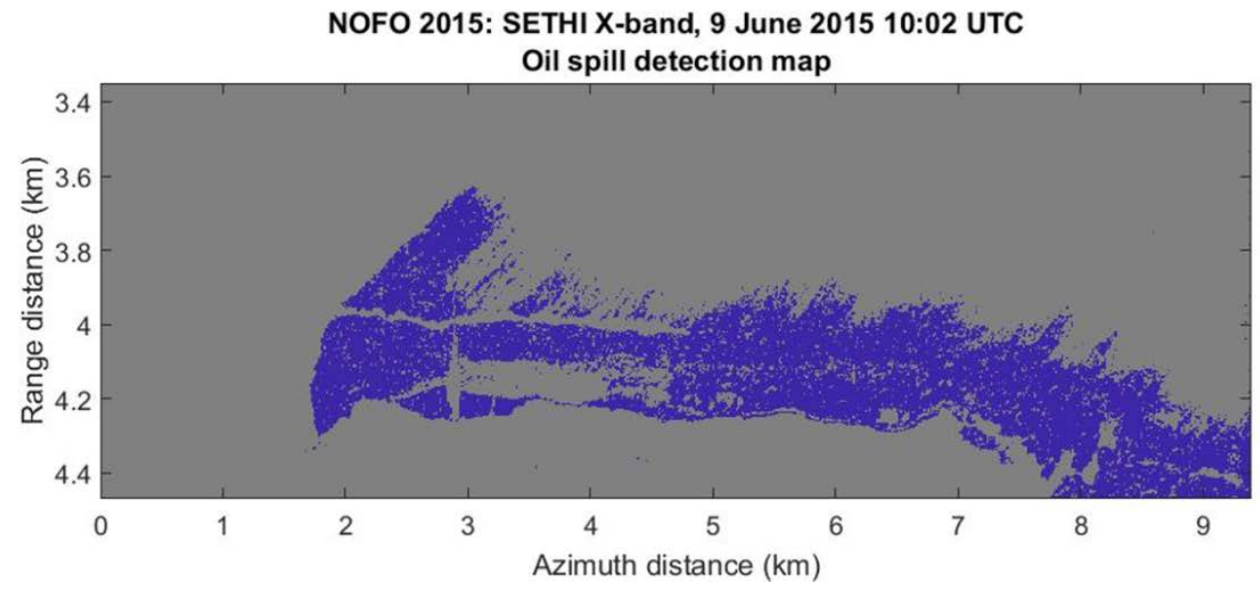

Figure 7: Oil spill map detected by thresholding the OI parameter - NOFO-2015

\section{Characterization}

Once the oil spill has been detected using X-band SAR data, information about the spilled product can be obtained with low frequency (e.g. L-band) polarimetric SAR images. Key information for authorities and petroleum companies that need to operate appropriate response to the released substance concern its behavior on the sea surface. SAR imagery can indicate whether the spilled product behaves like a viscoelastic film that is more or less homogenous and floating on the surface or if the spilled product is mixed with seawater within the upper few centimeters of the water column. The basic premise of this method [12], which yields the oil-water mixing index (M), is that radar backscattered power is diminished by oil slicks through mechanical damping of Bragg-wavelength gravity-capillary waves and reductions in the relative dielectric constant of the upper few centimeters near the sea surface. By decoupling the relative contribution to signal attenuation of mechanical damping of surface roughness and changes in dielectric constant, we can define the characteristics of the slick along a spectrum ranging from thin surface films to a product mixed with seawater within the water column. This has been demonstrated in the case of mineral oil [12] and chemical-related [7] offshore pollutant. The methodology initially reported in [12] has been applied on SAR data collected by SETHI at L-band during the NOFO exercise in 2015. The Oil and Water Mixing Index is shown Figure 8. Negative values (blue color) indicate that reduced EM amplitudes are due more to reduced relative dielectric constants than to damped surface roughness, meaning that the product is largely mixed with seawater. On the other hand, positive values (red color) indicate that the decreasing of the EM signal is mainly due to a smoothing of the ocean surface and thus product is primarily present as a film on the sea surface. For this acquisition, the wind direction is from the top right and images given Figure 1 show a feathered structure along the top of the slick, due to wind effect. A similar structure is observed on the Oil/Water Mixing Index (Figure 8), indicating that the heavier oil is moved by the wind (red color, lower part of the spill) while lighter oil is moved less by the wind [14] and mixed with seawater (blue color, upper part of the spill). 
NOFO 2015: SETHI L-band, 9 June 2015 10:02 UTC

Oil/Water mixing index

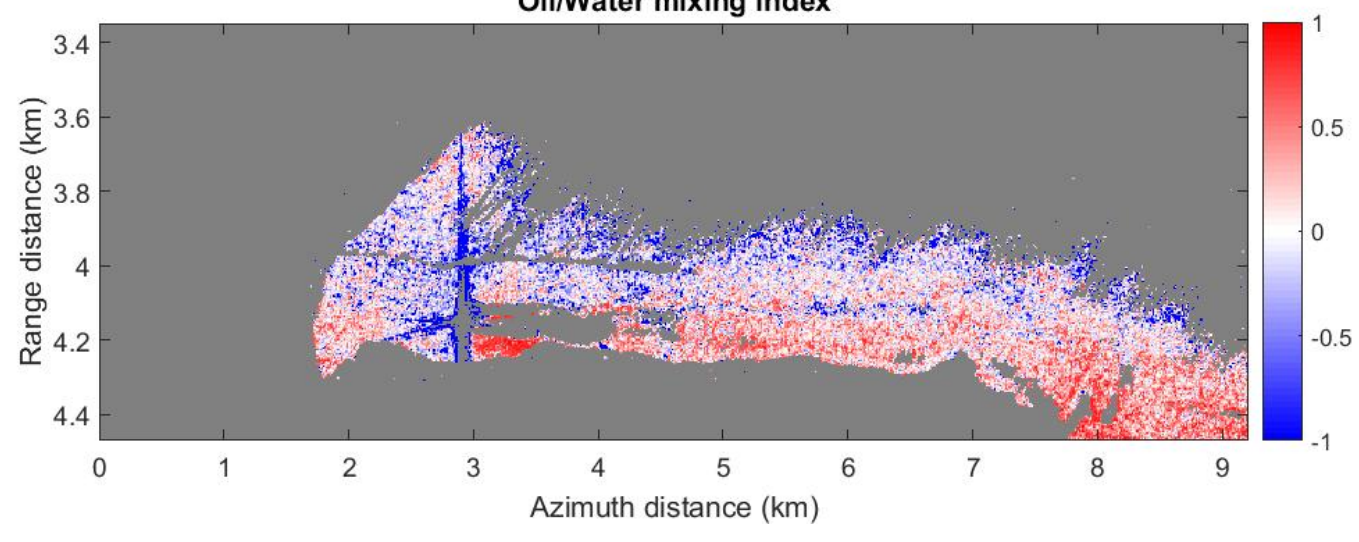

Figure 8: Oil/Water mixing index - NOFO-2015

\section{Quantification}

A model-based approach has been proposed in [8] to estimate the oil concentration within an oil-in-water mixture from L-band dual-pol SAR images. It is based on the pixel by pixel numerical inversion of the surface properties from the polarization ratio (PR) inferred by the Universal Weighted Curvature Approximation (UWCA) scattering model [15]. A simplification of the original method is reported on in [9], which makes it less time-consuming and no longer dependent on a reference clean sea image. This simplification, however, is made at the expense of the accuracy of the oil concentration estimate, especially for low percentages values of oil. Both methodologies are based on the joint use of a rigorous scattering model to predict the ratio between the dual-co-polarized channels (HH and VV) for L-band SAR images. The simplified method is applied herein to experimental data collected by SETHI during the NOFO-2015 experiment. The oil concentration is estimated by firstly, selecting, for each pixel, the closest value between the actual PR and those given by the U-WCA scattering model and then by finding the concentration rate corresponding to the modelled PR value (assuming a measured dielectric constant linked to the oil-only and water-only dielectric constant by the Bruggeman Formula [8]). The result is displayed in Figure 9. The mean value of oil content within the emulsion is equal to $52 \%$ and more than $80 \%$ of the pixels within the slick have a concentration between 40 and $65 \%$. Usually, the water content of marine oil slick lies between 50 and 75\% [16] corresponding to oil concentration between 50 and $25 \%$. The values obtained in this experiment are slightly higher, which could be due to the relative short time lag between the release of oil by NOFO at sea and the scene acquisition by the radar sensor.

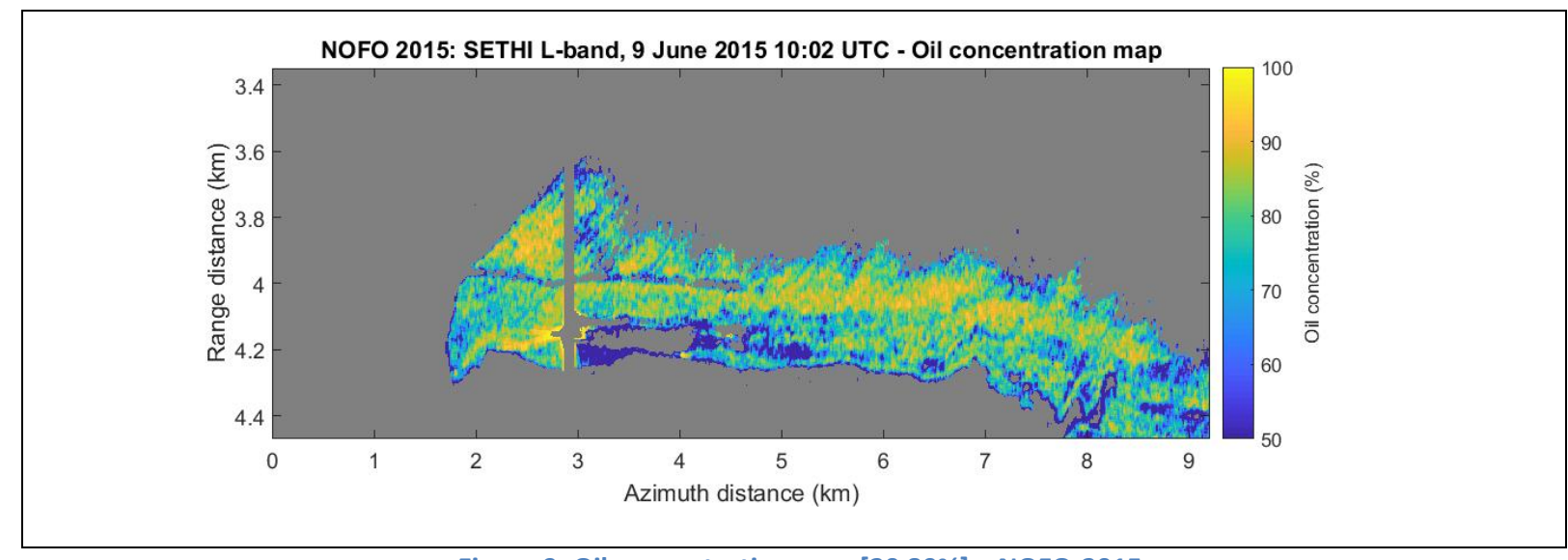

Figure 9: Oil concentration map [20 80\%] - NOFO-2015 


\subsection{Optical branch}

The order of the processing remains the same as for the radar branch, starting with detection, moving to characterization and ending with quantification.

\section{Detection}

The detection relies on indices computation. Table 3 summarizes the indices implemented. The blue ones have been defined by ONERA in the frame of NAOMI project. A benefit of the NAOMI project is the automatic thresholding of indices implemented to distinguish oil or emulsion from water.

\begin{tabular}{|l|l|c|}
\hline \multirow{2}{*}{ VNIR } & FI : Fluorescence Index [1] & $\left(\rho_{0,47}-\rho_{0,67}\right) /\left(\rho_{0,47}+\rho_{0,67}\right)$ \\
\cline { 2 - 3 } & RAI : Rotation-Absorption Index [1] & $\|\rho\|\left(\rho_{0,47}-\rho_{0,85}\right) /\left(\rho_{0,47}+\rho_{0,85}\right)$ \\
\cline { 2 - 3 } & nFI : normalized FI [10] & $\|\rho\|\left(\rho_{0,47}-\rho_{0,67}\right) /\left(\rho_{0,47}+\rho_{0,67}\right)$ \\
\hline \multirow{3}{*}{ SWIR } & HI : Hydrocarbon Index [15] & $\frac{(1,72-1,67)}{(1,75-1,67)}\left(\rho_{1,75}-\rho_{1,67}\right)+\rho_{1,67}-\rho_{1,72}$ \\
\cline { 2 - 3 } & Aire $1700[16]$ & surface under the continuum between 1,66 and \\
\cline { 2 - 3 } & Aire 2300 [16] & surface under the continuum between 2,21 and \\
& & $2,38 \mu$ mm \\
\cline { 2 - 3 } & SWIRsat & To be published \\
\hline
\end{tabular}

Table 2: Spectral indices computed in the detection step

Figure 10 illustrates the results obtained with the FI for various kinds of optical images, starting from CEDRE pool and moving to real satellite image. For the available data, FI also enables to distinguish seaweeds from oil.

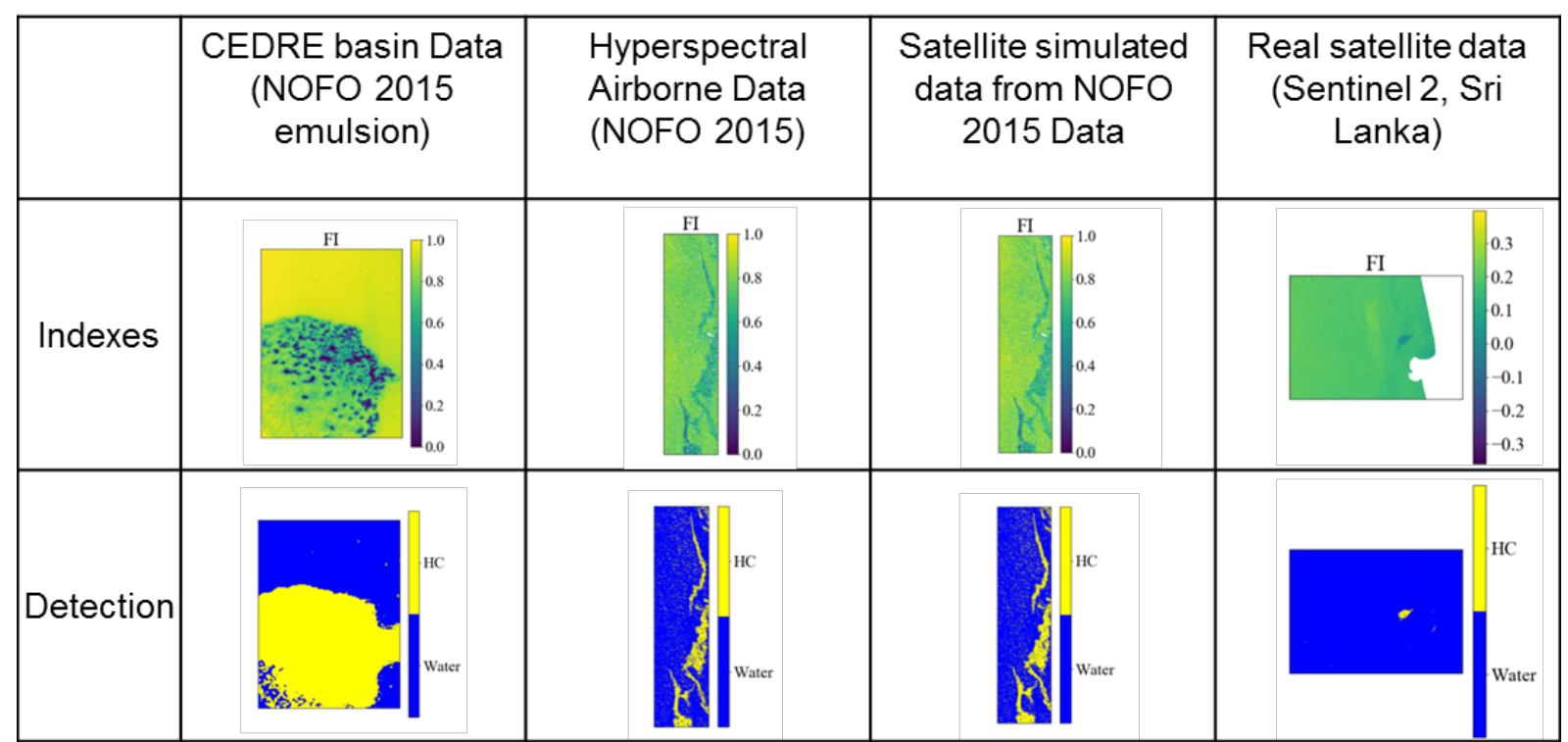

Figure 10: Oil or water-in-oil emulsion detection thanks to Fl for various kinds of optical images 


\section{Characterization}

The second step of the process is the segmentation of the index values, mainly the FI, inside the slick. If one threshold is chosen, leading to 2 classes, the segmentation usually enables to distinguish thin and thick parts of the slick as shown in Figure 11.
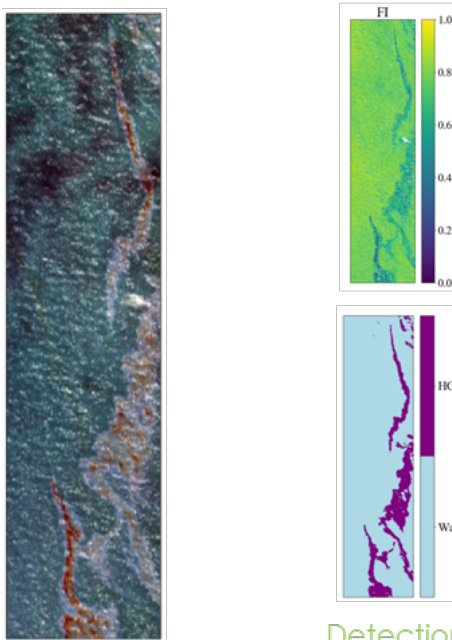

Detection
Characterization from indices

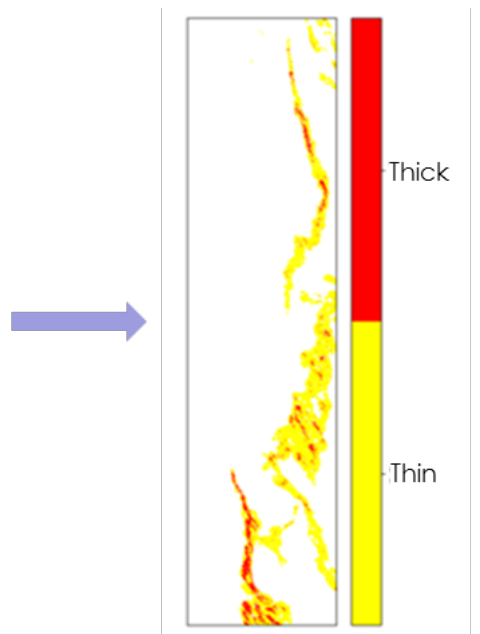

Distinction thicks/thin areas (2 classes)

Figure 11: Characterization of a NOFO2015 slick (distinction of thin and thick areas) thanks to Fl segmentation

If a reference spectral database is available, a second step for characterization is the product identification by comparing its spectral signature to the signatures of this database. Two libraries were built during the NAOMI project, one from laboratory measurement and associated modelling and the other one thanks to pool experiment. For the NOFO2015 airborne image of Figure 11, Spectral Angle Mapper (SAM) and Spectral Information Divergence (SID) and CHI2 enable to identify the NOFO emulsion thanks to the laboratory library and the thicker parts of the slick. The Orthogonal Projection Distance (OPD) makes confusion between thinner part of the slick and sunflower oil.

\begin{tabular}{|l|l|l|l|}
\hline & Hyperspectral & S2 & Landsat 8 \\
\hline SAM & $86 \%$ & $83 \%$ & $73 \%$ \\
\hline OPD & $33 \%$ & $39 \%$ & $41 \%$ \\
\hline CHI2 & $82 \%$ & $79 \%$ & $73 \%$ \\
\hline SID & $88 \%$ & $94 \%$ & $86 \%$ \\
\hline
\end{tabular}

Table 3: Percentage of pixels with adequate classification for the laboratory library

\section{Quantification}

The last step of the optical branch of the workflow is the quantification. If the product is identified and is part of the products studied during the pool experiment, a mean thickness value can be derived from this experiment for the thin and the thick pixels respectively. These mean thicknesses can then be assigned to the thin and thick classes provided by the characterization step for the processed real case image. The volume is estimated by computing the surface covered by the pixels for each class and multiplying this surface by the assigned mean 
thickness of the class. This exercise has been done for a NOFO2015 large slick using segmentation of FI and is reported in Table 4.

\begin{tabular}{|l|c|c|c|}
\hline & Thick & Thin & Total \\
\hline Surface $\left(\mathrm{m}^{2}\right)$ & 13533 & 109007 & 122540 \\
\hline Volume $\left(\mathrm{m}^{3}\right)$ & 14.9 & 2.7 & 17.6 \\
\hline
\end{tabular}

Table 4: Volume assessment for a slick of a NOFO2015 image using thicknesses from pool experiment

\section{CONCLUSION}

The improvements in detection, characterization and quantification of offshore slicks are mostly due to the joint experimental and theoretical approaches developed during all the NAOMI project long. These improvements have led to new tools which have been tested on the wealthy data set constituted during the project, including pool images with a fairly good ground truth, and airborne and space-borne images.

In the optical domain, the synergy between experimental and theoretical approaches started for laboratory measurements. Modelling of laboratory measurements made possible the adaptation of the laboratory spectral signatures to the in-situ conditions: the background can be very reflective for the laboratory measurements in order to get a high signal to noise ratio and may need to be replaced by the adequate background when constituting the spectral library for product identification. The model can also be used to adjust the thickness in the range of sensitivity to extinction. Modelling of pool measurements for pure products helped to understand the relative weights of contributor to the observed signal and to initiate recommendations for imaging conditions.

Modelling of the emulsion is still on progress. It is planned to use the signature simulated by the model to study the sensitivity of the spectral signature to the water content and the droplets size.

The work performed with signatures led us to propose two main new indices in the SWIR domain for robustness improvement compare to HI. The analysis of the images provided by FI enabled first to implement an automatic thresholding of the index image in order to detect the oil that is to say discriminate oil from water and second to segment the slick into classes to characterize the slick in term of thickness. Identification of products existing in the spectral library can be done using spectral distances such as SAM and SID. For identified product a fairly realistic slick volume assessment can be estimated thanks to association of thickness to each class, thickness being deduced from pool experiment.

In the radar domain, firstly, progress has been done in identifying the most efficient modes of acquisition for offshore hydrocarbons detection. Then, a methodology to automatically detect oil at sea has been proposed, whatever its behavior once released on the maritime environment, as well as measuring the effectiveness of cleaning operation in progress, what is crucial in an HSE context. Then, a sophisticated method, relying on Lband radar imagery and previously published in [12], is reported herein to identify pixels covered by a film that is to say oil at the surface and the ones for which the oil may be as droplets in the volume. Finally, SAR imagery collected at low frequency (e.g. L-band) as proven to allow an estimation of the oil concentration within and oil and seawater mixture [8][9].

For the future, a lot of work remains to do in particular to draw benefits of radar and optical imagery.

\section{ACKNOWLEDGMENTS}

This work was carried out in the framework of the NAOMI research project a partnership between TOTAL and ONERA. We would like to thank the NOFO, the CEDRE and all the persons, including ONERA \& TOTAL colleagues, involved in the two experiments. 


\section{REFERENCES}

[1] Brekke C., Solberg, A., “Oil spill detection by satellite remote sensing”, Remote Sensing of Environment, 95, 113,2005.

[2] Fingas M., Brown C., "Review of oil spill remote sensing”, Marine Pollution Bull., 83, 9-23, 2014.

[3] Lennon M., Mariette V., Coat A., Verbeque V., Mouge P., Borstad G. A., Willis P., Kerr R and Alvarez M., "Detection and mapping of the November 2002 Prestige tanker oil spill in Galicia, Spain, with the airborne multispectral CASI sensor," $3^{\text {rd }}$ EARSEL workshop on Imaging Spectroscopy, 2003.

[4] Clark R., Swayze G., Leifer I., Livo K., Kokaly R., Hoefen T., Lundeen S., Eastwood M., Green R., Pearson N., Sarture C., McCubbin I, Roberts D., Bradley E., Steele D., Ryan T., Dominguez R., and the airborne Visible/Infrared Imaging Spectrometer (AVIRIS) team, “A method for quantitative mapping of thick oil spills using imaging spectrometry,” Open File Report of USGS, 1-44, 2010.

[5] Leifer I., Lehr W. J., Simecek-Beatty D., Bradley E., Clark R., Dennison P., Hu Y., Matheson S., Jones C. E., Holt B., Reif M., Roberts D. A., Svejkovsky J., Swayze G., and Wozencraft J., "State of the art satellite and airborne marine oil spill remote sensing: Application to the BP Deepwater Horizon oil spill,” Remote Sensing of Environment 124, 185-209, 2012.

[6] Sicot G., Lennon M., Miegebielle V. and Dubucq D., "Analysis of reflectance spectra of oil emulsion spilled on the sea surface," Proc. SPIE 9240, 1-10, 2014.

[7] Angelliaume S., Minchew B., Chataing S., Martineau P. and Miegebielle V., "Multifrequency Radar Imagery and Characterization of Hazardous and Noxious Substances at Sea," in IEEE Transactions on Geoscience and Remote Sensing, vol. 55, no. 5, pp. 3051-3066, May 2017.

[8] Boisot O., Angelliaume S., and Guérin C.-A., "Marine Oil Slicks Quantification From L-band Dual-Polarization SAR Imagery," IEEE Transactions on Geoscience and Remote Sensing, vol. 57, pp. 2187-2197, 2019.

[9] Angelliaume S., Boisot O., and Guérin C.-A., "Dual-Polarized L-Band SAR Imagery for Temporal Monitoring of Marine Oil Slick Concentration," Remote Sensing, vol. 10, 2018.

[10] Angelliaume, S., Ceamanos, X., Viallefont-Robinet, F., Baqué, R., Déliot, P. and Miegebielle, V., “Hyperspectral and Radar Airborne Imagery over Controlled Release of Oil at Sea,” Sensors 2017, 17(8), 1772 (2017).

[11] Viallefont-Robinet F., Moussous A., Déliot P., Roupioz L., Miegebielle V., " Analysis of water-in-oil emulsion hyperspectral signature: contribution of pool experiment," Proc. SPIE Volume 10784, Remote Sensing of the Ocean, Sea Ice, Coastal Waters, and Large Water Regions 2018; 107840C (2018) https://doi.org/10.1117/12.2324865

[12] Minchew B., "Determining the mixing of oil and seawater using polarimetric synthetic aperture radar," in Geophys. Res. Lett., 39, L16607, 2012.

[13] Angelliaume S., Dubois-Fernandez P. C., Jones C. E., Holt B., Minchew B., Amri E., et al., "SAR Imagery for Detecting Sea Surface Slicks: Performance Assessment of Polarization-Dependent Parameters," IEEE Transactions on Geoscience and Remote Sensing, vol. 56, pp. 4237-4257, 2018.

[14] https://earth.esa.int/web/guest/events/-/asset_publisher/5YrWLNknVkVH/content/oilpollution/maximized;jsessionid=61F6D9E52FE3E72AA4A6D24545220465?redirect=https\%3A\%2F\%2Fearth.e sa.int\%2Fweb\%2Fguest\%2Fevents\%3Bjsessionid\%3D61F6D9E52FE3E72AA4A6D24545220465\%3Fp_p_id\% 3D101_INSTANCE_5YrWLNknVkVH\%26p_p_lifecycle\%3D0\%26p_p_state\%3Dmaximized\%26p_p_mode\% 3Dview\%26_101_INSTANCE_5YrWLNknVkVH_struts_action\%3D\%252Fasset_publisher\%252Fview.

[15] Guerin, C.-A.; Soriano, G.; Chapron, B. The weighted curvature approximation in scattering from sea surfaces. Waves Random Complex Media 2010, 20, 364-384.

[16]Fingas M., Fieldhouse B., "Studies on water-in-oil products from crude oils and petroleum products”, Mar. Pollut. Bull., 64, 272-283, 2012.

[17] Kühn F., Oppermann K., Hoerig B., “Hydrocarbon Index-An algorithm for hyperspectral detection of hydrocarbons, “Int. J. Remote Sens., 25, 2467-2473, 2004.

[18] Achard V., Elin C., "Automatic mapping of hydrocarbon pollution based on hyperspectral imaging", to be published at IGARSS 2019. 